\title{
T-REX: The Teachers' Research Exchange. Overcoming the Research-Practice Gap in Education.
}

\section{Marek McGann ${ }^{1}$, Marie Ryan², Jennifer McMahon ${ }^{3}$, and Tony Hall ${ }^{4}$}

${ }^{1}$ Department of Psychology, Mary Immaculate College, Limerick. Email: marek.mcgann@mic.ul.ie

${ }^{2}$ Department of Reflective Pedagogy and Early Childhood Studies, Mary Immaculate College, Limerick.

${ }^{3}$ School of Education, University of Limerick.

${ }^{4}$ School of Education, National University of Ireland, Galway.

\begin{abstract}
This paper introduces the Teachers' Research Exchange (T-REX), an online community of practice that is currently being deployed on a pilot basis nationwide in Ireland as a response to the "research-practice gap". The system includes collaborative, educational, and technical components. The technical aspect is the social networking and sharing platform for educational research stakeholders of all kinds. Tools for collaboration and learning available on the platform are designed for a range of users from different professional backgrounds. Crucially, these resources are complemented by a programme of structured collaborative activities to foster a novel community of practice involving pre-service teachers, practising teachers, researchers in higher education, and other educational research stakeholders. Several examples of current use are outlined to illustrate the potential for this model to support collaboration between otherwise siloed professional groups.

Keywords: community of practice, initial teacher education, online platform, research-practice gap, teacher researchers
\end{abstract}

\section{Introduction}

Both working teachers and educational researchers are keenly aware of the research-practice gap - the lack of contact between the products and conclusions of research in the field, and professional activity in schools and colleges. The "research-practice gap" is a term to describe the fact that no clear framework exists by which research findings become integrated in systematically into educational practice, and educational practice is neither systematically integrated into the processes of developing and answering research questions. Perhaps most famously examined by Hargreaves (1996) as the "fatal flaw in educational research", it remains an issue of concern for both researchers and practitioners alike (Biesta, 2010; Broekkamp van Hout-Wolters, 2007; Coburn, Penuel, Geil, 2013; Cochran-Smith Lytle, 1999; Godrey, 2016; Gore Gitlin, 2004; Hammersley, 1997; MacPhail O'Sullivan, 2019; Schwartz Gerlach, 2011; Slavin, 2008; Vanderlinde van Braak, 2010; Walker et al., 2018). The number of varied perspectives that have been developed to explain the prevalence and persistence of this gap (Cain, 2015; Hammersly, 2003; Levin, 2004; McIntyre, 2005;

PREPRINT (2020)

DOI:

$10.1007 / \mathrm{s} 11528-020-00486-4$

Correspondence

Marek McGann

Edited by

(c) The Author(s) 2020. Ulichny Shoener, 1996; Vanderlinde van Braak, 2010) indicate that the problem is a complex one. Effectively addressing it will require an approach that coherently integrates a number of measures to facilitate cultural change and development of practice within all of the professions involved. Overcoming the gap has nevertheless become a key consideration for policy and professional development in a number of countries, where evidence-based practice has been identified as key priority (e.g British Education Research, Royal Society of Arts, 2014a, b; OECD, 2007; Teaching Council of Ireland, 2011). 
In this paper we briefly examine some of the salient characteristics of the research-practice gap in order to identify a constellation of factors that play a role in maintaining it despite the problem's recognition, and the clearly evidenced appetite to overcome it. We then provide a detailed introduction to a recently developed response to the gap that is being deployed in the Irish education sector, but the features of which could be localised to any given educational professional environment. The project is the Teachers' Research Exchange (T-REX)1, an online community of practice for educational research and practice sharing that is integrated with Initial Teacher Education (ITE) programmes, and facilitates inter-disciplinary collaboration across a number of professional boundaries.

\section{The Research-Practice Gap: A Professional Challenge}

The research-practice gap has seen a substantial literature develop over the past two decades (though the need to address the relationship has been discussed for much longer, see for example Stenhouse, 1975, 1981). Within this literature, a number of factors have been identified as playing a role in maintaining the disjunction. These include practical constraints, notably the limited time available to teachers to engage with research outside of immediate class-related activities (See et al., 2016) and often the availability of research, much of which is behind costly paywalls. These practical considerations are exacerbated by sociological and cultural differences between the various professions involved. Differences in professional dialect make the technical vocabularies, and often just poor writing, of academic research a barrier to the engaged teacher (See et al., 2016), while differences of values and epistemologies ensure that the purposes of research are often quite distinct for the various groups (McIntyre, 2005). While researchers seek generalities and examine broad strategic considerations of what matters in education and learning, teachers consider particularities, the in-context decision making where generalities may not apply (Biesta, 2007; Hammersley, 1997, 2005). McIntyre (2005) describes this as a difference between researchers "knowing that", while teachers "know how", where academic work provides a description of educational phenomena in general, while teachers implement actions in specific class settings. Finally, differences in the relative prestige of university-based vs. schools-based knowledge provide a perceived gap in the value of that knowledge, and creates a barrier to full engagement between the professions on a basis of mutual recognition. Mockler (2011) and Davies (2003), for example, both raise concerns that academic research often plays a controlling, rather than enabling role in the teaching profession. Joram (2007) notes that teachers often take a somewhat different view of the generalisability and falsifiability of research conclusions than do university-based researchers, while the likes of Anderson and Herr (2011) offer arguments that strict adherence to standardised, evidence-based models of teacher expertise undermines teachers in favour of the imposition of problematically rigid models of education.

The multifarious and systemic character of these challenges ensures that there is no quick, and no singular, fix for the research-practice gap. The literature to date makes it clear that closing the gap will require systemic, cultural change that improves the communication and coordination between the various professions with a stake in educational research (Farley-Ripple, May, Karpyn, Tilley, McDonough, 2018).

Systemic change is more like making a tide than making waves. It demands a multifaceted approach that ranges from adoption of broad policies that create professional context fertile for change, to gradual transformation of the professions involved that will increase coordination between domains, and change the practice of the individuals who instantiate these professional domains. To create dialogues in which the diversity of professional voices are respected, while facilitating the transformation of identities and practice over time, requires action at the broad policy level, at the level of interaction between professional groups, and the individual practices of working professionals (Penuel, 2015; 2019). More, the changes at these different levels must be 
sufficiently coherent as not to create new unsuperable tensions. Bringing the groups into increased coordination with one another without riding roughshod over their differences, that is respecting the diversity of voices in the dialogue, will require the development of new communities of practice where such dialogue is normalised (as has been recognised by the likes of Broekkamp and van Hout-Wolters, 2007).

Policy changes at a national level in many countries have already been put in place. Though these have tended to affect the teaching profession more directly, with "evidence-based practice" becoming a buzz-phrase in the discipline, the increased requirement for academic research to show "impact" shapes the researchers' activities in related, complementary ways. The ideas of research impact and evidence-based practice are in themselves laudable, but to avoid becoming hollow terms, the practices of the different groups will have to come more into alignment.

As relevant policies vary from country to country, the particular configurations of impetus and constraint will be specific to local context. Regardless of these differences, though, a new community of practice will still need support from professional structures, and scaffolding for new activities during the period of its development (Wenger, McDermott, Snyder, 2002).

In addition to these powerful (if somewhat nebulous) professional and organisational considerations, are the more mundane practical issues, such as people's limited time, access to research resources, and the challenge of interaction when members of community are scattered across different institutions and geographical areas.

In the next section we introduce the Teachers' Research Exchange (T-REX), an online community of practice currently in a pilot phase of development and deployment in Ireland which has been designed with these various constraints in mind, in order to cultivate a new community of practice for educational research that involves the full range of stakeholder professions in that domain.

\section{T-REX - An Online Community of Practice for Educational Research}

The Teacher's Research Exchange is a project with collaborative, educational, and technical aspects. It has been designed to help overcome the research-practice gap through the supporting of systemic change in research engagement and research activity within the educational sector. This is being deployed initially in Ireland, but the model is generic, and may apply in other locales and professional settings too.

Systemic change demands an approach that is both multifaceted and sustained. Not so much an intervention, as the construction of new infrastructure, or more appropriately, the cultivation of a new community. To better conceptualise this process, we have drawn on Wenger's (1998; Wenger et al. 2002; see also the original development of the concept in Lave Wenger, 1991) notion of a community of practice, for which there are three key elements (see Figure 1): a domain, a community, and practice. We take each of these in turn.

\subsection{The Domain: Educational Research}

T-REX was conceived as a means of supporting cultural change in research engagement and evidence-informed professional activity in teaching in Ireland. The context of its development in Ireland involves changes in policies at the national level (Inspectorate, Department of Education and Skills, 2016), changes in training and qualifications accreditation requirements mandating research engagement in Initial Teacher Education programmes (The Teaching Council of Ireland, 2011, 2017), and a growing appetite amongst practising teachers for more engagement with research.

While it is easy to put a label on the domain, that is "educational research", precisely what this means will be determined over time; not by stipulation in policy, but by the actions of community members. This is in recognition of the complexity of this concept across different settings and professional groups (e.g. McIntyre, 2005; Nisbet, 2005). In setting out to facilitate the development 

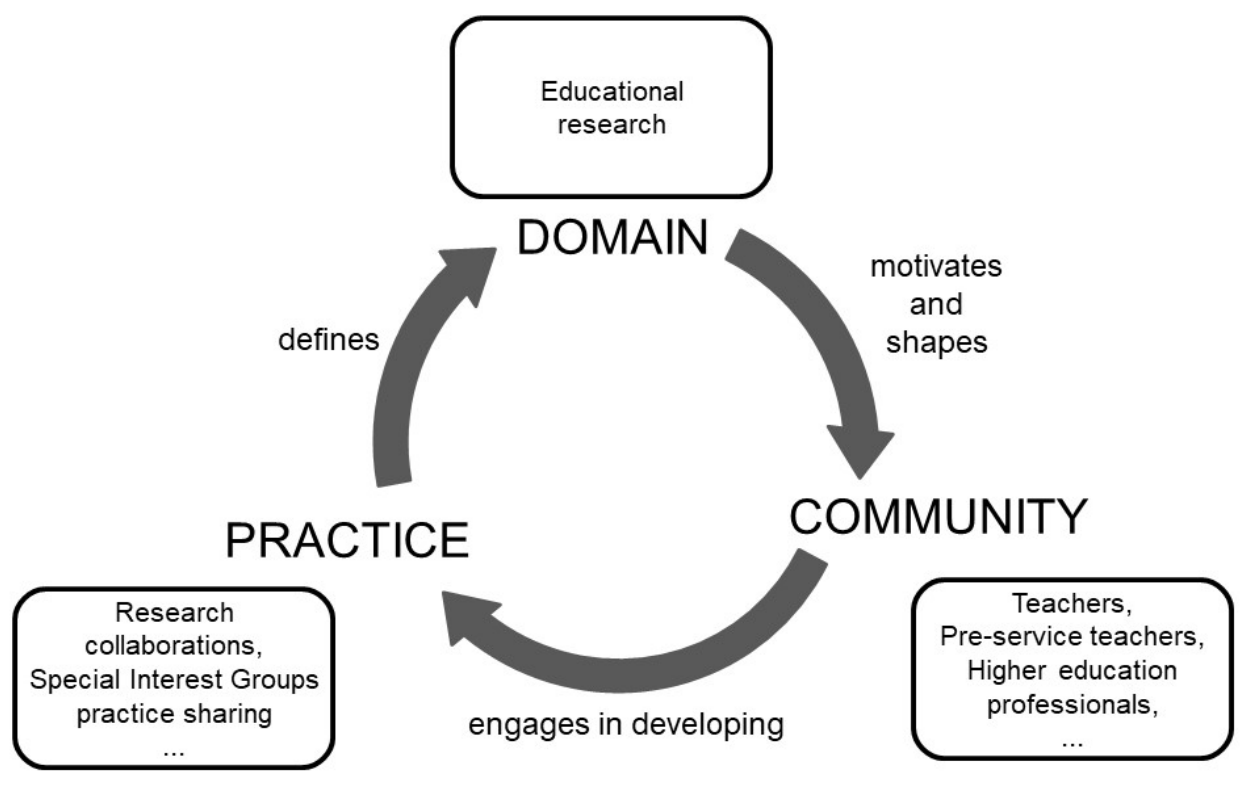

Figure 1. The three components of a community of practice, and their relationship in the case of the Teachers' Research Exchange (T-REX)

of a new community of practice, however, policies at national or similarly broad levels can play a role in raising awareness and orienting potential community members towards the domain as broadly conceived. This kind of orientation is vital for the flourishing of the kind of joint enterprise that defines the domain in question.

At present in statements on mission and policy for T-REX, research is not defined, but rather pointed to and recognised. The aim is inclusivity, allowing both "big R" and "small r" research adequate place in the discussion. Furthermore, it is timely because increasingly both big and small data research are being promoted and valorized in the educational community. Sahlberg and Hasak (2016) note the importance of the two types of research: the small but powerful data of classroom and school-based research, alongside what might traditionally have been conceived of as academic educational research, the big data of larger scale studies and surveys.

Making such space means overcoming some of the challenges noted above as being associated with the research-practice gap generally. While this policy context clearly favours the development of a more robust and continuously research-involved teaching profession, during initial discussions with stakeholders a number of constraints were identified that prevented the flourishing of this developing culture, constraints that echoed those long recognised regarding the research-practice gap. Firstly, and most notably, was the limitation of people's time. Teachers are not a group of people known for having swathes of spare time at their disposal to enable their participation in methodological training programmes, or research agendas; quite the contrary. Secondly, while teachers have shown an increasing appetite for research engagement, there is not a strong history of such engagement within the profession. Though it is growing, there is not yet much of a history of the expertise required embedded or widespread within the extant community. As such. the basic infrastructure and supports for such engagement that might be necessary are at a premium, or absent entirely. The nascent character of the research culture amongst teachers also means that those interested in developing this aspect of their professional practice can often find themselves practically and geographically distant from others with similar interests.

While clearly challenging, these professional realities were identified by the development team as complementary to challenges faced by both university-based educational researchers, and pre-service teachers studying on newly adapted programmes of Initial Teacher Education. Higher 
education-based researchers are continually searching for professional partners, who have access to the applied environments that must ultimately provide the test of their theories and hypotheses. Despite the need of educational researchers for teaching partners, and teachers for the support of educational researchers, however, the professional networks of each tend not to overlap, and opportunities for encounter or interaction between the two are surprisingly rare (indeed, this is precisely the reality behind the research-practice gap).

The problem is magnified by the fact that the number of educational researchers in Ireland has increased significantly in the past seven years due to the mandating of research activity on Initial Teacher Education programmes, and the reconfiguation of graduate ITE programmes from a one-year, diploma model to a two-year and research-based, Professional Masters in Education. Student teachers involved in revised ITE programmes are now required to be research engaged or research active, in a way that does not fit with their intuitive conceptions of the teaching profession, and which also does not clearly fit together with their typical experiences on school placement and teaching practice during their studies. Nevertheless, during their time as pre-service teachers at least, they spend at least some periods as educational researchers, under the guidance of more senior university-based researchers.

T-REX is an attempt to bring these complementary challenges together to support the development of a coherent domain of practice. It was conceived as a "digital bridge" that can in principle provide a means for these interdependent but still too-isolated groups to come together in joint enterprise. It is an online social network and collaboration space for in-service teacher researchers, pre-service (student) teacher researchers, and researchers in higher education institutions.

Several online platforms for professional dialogue have been developed over the past two decades, particularly in the U.S. Such networks tend to have quite a specific, often pedagogical focus, either in terms of national goals such as integration of technology into the classroom (the aim of a range of "PT3" projects in the U.S., see Mims, Polly, Shepherd Inan, 2006 for a review), or the development of teaching resources and examination of related techniques (e.g. mathforum.org, as outlined by Renninger Shumar, 2004, or Ireland's National Digital Learning Respository; McAvinia Maguire, 2011). These examples also illustrate the strong emphasis on professional development of teachers, and peer-to-peer collaboration (e.g. in the Inquiry Learning Forum for practice sharing and discussion developed by Barab, Makinster, Moor Cunningham, 2001).

Where collaboration between different professional groups, or between both students and teachers, the emphasis is once again on pedagogy (e.g. Bitter, Puglisi, Gorges Uppal, 2016's work with online collaborative learning games). To overcome the research-practice gap, however, such collaborations will need to be maintain the possibility of peer-to-peer interaction, but across professional domains, not in the service of one group's learning, but in the service of all professions coordinating their efforts and managing a division of labour according to the needs of education ressearch. A previously existing model of such activity might be the TappedIn platform developed by Schalger, Fusco, Schank (2002a; see also Schlager, Fusco, Schank, 2002b; Schlager Fusco, 2003), which provided a virtual campus within which a range of professions (teachers, librarians, administrators and others) were able to collaborate. The project ran from 1997 to 2013. In that instance, the emphasis was primarily on the professional development of teachers. In the case of T-REX, however, rather than having a focus just on outcomes for one key profession, the aim is to develop an integrated community of education researchers across multiple professions. In a manner in consonance with recently published guidelines for the cultivation of online communities of practice (U.S. Department of Education, 2016), we begin with a vision identifying the domain for the community. 


\section{Underlying principles}

Through early conversations with various stakeholders and potential members of the community, we have outlined a number of principles (informed by Wenger et al., 2002) that help structure how we think about the domain of practice, and which guide decisions regarding technical functionality, and scaffolded activities in the fostering of community development.

- T-REX recognises that academic researchers, student researchers, and teachers all have essential roles to play in the generation and use of research. The research process is best manifested as a two-way (or more) interaction rather than a one-way dissemination of research i.e. teachers are considered partners in the research process rather than as consumers. Academic researchers and teachers may have distinct roles within the research process, but these roles may be interchangeable and project dependent. This helps to address the challenges of inclusivity and diversity, and ensure a dialogical character to the newly developing domain that respects the already existing communities of practice within the various professions.

- T-REX is not just a knowledge store or online library of condensed, easy to consume research bites. T-REX seeks to establish an active, vibrant community of people interested in generating and using educational research. The emphasis is on communication and sharing among the participating professionals.

- T-REX seeks to promote teachers' professional autonomy. Research and data within the T-REX community is not about teacher evaluation but rather should be used to empower teachers to evaluate, develop, and refine practice for themselves. This helps ensure that the community can develop around shared values, which might change naturally over time, rather than an attempt to impose change in a top-down fashion.

- T-REX seeks to democratise the educational research agenda. It recognises a broad spectrum of what counts as research and what research should be shared. Research engagement often does not involve primary data collection (e.g. in the case of reviews of literature, or professional problem-solving).

For the community to grow, it requires not just a policy directive, but engagement with the domain by relevant professionals. The second component of a community of practice, then, is the community itself.

\section{The Community: Stakeholder professions in educational research}

A community of practice is not simply a group of people with similar interests, but a group of people who interact with one another around those interests (Wenger, 1998), that is mutual engagement in a joint enterprise. Members of a community communicate, share, and collaborate. There may be division of labour, and structure to the interaction such that newcomers have more peripheral, though still legitimate, roles to play, while old-timers fulfill requirements for leadership, mentorship, and support (Lave Wenger, 1991; Wenger et al., 2002). Regardless of the specific shape that the community takes, there is such structure to it, channels through which the various voices can converse, and means by which the various members can coordinate their shared activities. Community thus involves both the members and the infrastructure that supports their endeavours. Where communities of practice are local, physical places perform this vital function. Places are adapted to support particular activities (Schoggen, 1989; Heft, 2001), while proximity enables easy communication and collaboration (Lee, Brownstein, Mills, Kohane, 2010).

Where members of the community are more distant from one another, things are different, but such distributed organisations can still thrive. It is one of the internet's greatest strengths that it can provide means for more far-flung groups to form effective communities of practice, though it is important to recognise the role of places and channels of communication that are fit for the variety of purposes extant within a given community. And of course, the infrastructure alone does not form a community any more than a set of roads by themselves make a town. In developing T-REX, 
then, the purpose of the technological infrastructure to support interaction, coordination, and collaboration between members in a variety of ways was continuously emphasised. The intention is the provision of resources that can be adopted, and adapted, for a variety of uses depending on members' needs. Members' engagement has not just been left to chance, however (as though with a kind of "build it and they will come" approach), but has been supported by a range of activities involving diverse groups of professionals.

\subsection{Infrastructure for inter-professional dialogues}

The ideal case for a research community is one which enables physical proximity between its members (Lee, et al., 2010). Given the challenge of geographical spread as regards the educational research community noted above, the natural choice was the cultivation of an online community of practice, one within which members can find others of similar interests, discover research and other content relevant to their research needs, and engage in collaborative activities.

There can be no fixed end-point identified for the community (at which time everyone will have some "correct" level of knowledge) but rather a division and coordination of labour that overcomes the identified challenges and enables a richer understanding and ever more successful engagement with the demands of education at all levels on an on-going basis. It is not about the provision of expertise by one group to another, but an effective exchange of different forms of research expertise.

Developed with such an ultimate ideal in mind T-REX has been developed with BuddyPress (Jacoby, Gorges, Gibbs, others, 2018) and related open source technologies (a development of the WordPress content management system that has become the backbone of much of the web).

T-REX operates in a manner similar to other social networks, and as such, offers new members a familiarity that provides a low barrier to engagement. With the intention of supporting a community of research practice amongst its members, the system includes a number of different elements which provide more and less structured potential activities, models of use, and resources for engagement with and in educational research. The technology offers a scaffold, but the community is, and can only be, its members.

Members of the community hail from a diverse range of professions with a stake in educational research. In-service teacher members range in experience from Newly Qualified Teachers (NQTs) to seasoned professionals with more than 30 years of practice. Professionals also come from all stages of education, from early years education, to primary, post-primary, and adult or further education. Pre-service teachers are undergraduates at various stages of their professional preparations - from first to fourth year of their studies. Pre-service teachers' engagement tends to occur in projectspecific groups of students at the same level of study, collaborating with other members, either fellow students, in-service teachers, or higher educational researchers.

Higher education professional interact with the platform both as leaders of academic modules and courses, and also as specialists in research and research methods.

Membership also includes professionals from administrative and services organisations for education.

Acknowledging this diversity of membership, the online platform is hosted independently of any particular institution. It thus takes advantage of the internet's capacity to overcome geographical separation without introducing new barriers to entry such as requiring members to obtain institutional credentials to participate. For example, a teacher in the town of Port Laoise in the centre of Ireland can simultaneously collaborate on a project with researchers in Mary Immaculate College in Limerick in the south west of the country, and with Marino Institute of Education in Dublin on the east coast, without needing institutional accounts in either. The platform is open to all registered teachers in Ireland (though expansion to include educators from other countries is not a present aim of the project, nothing in the structure or operation of the technology necessarily precludes it - 


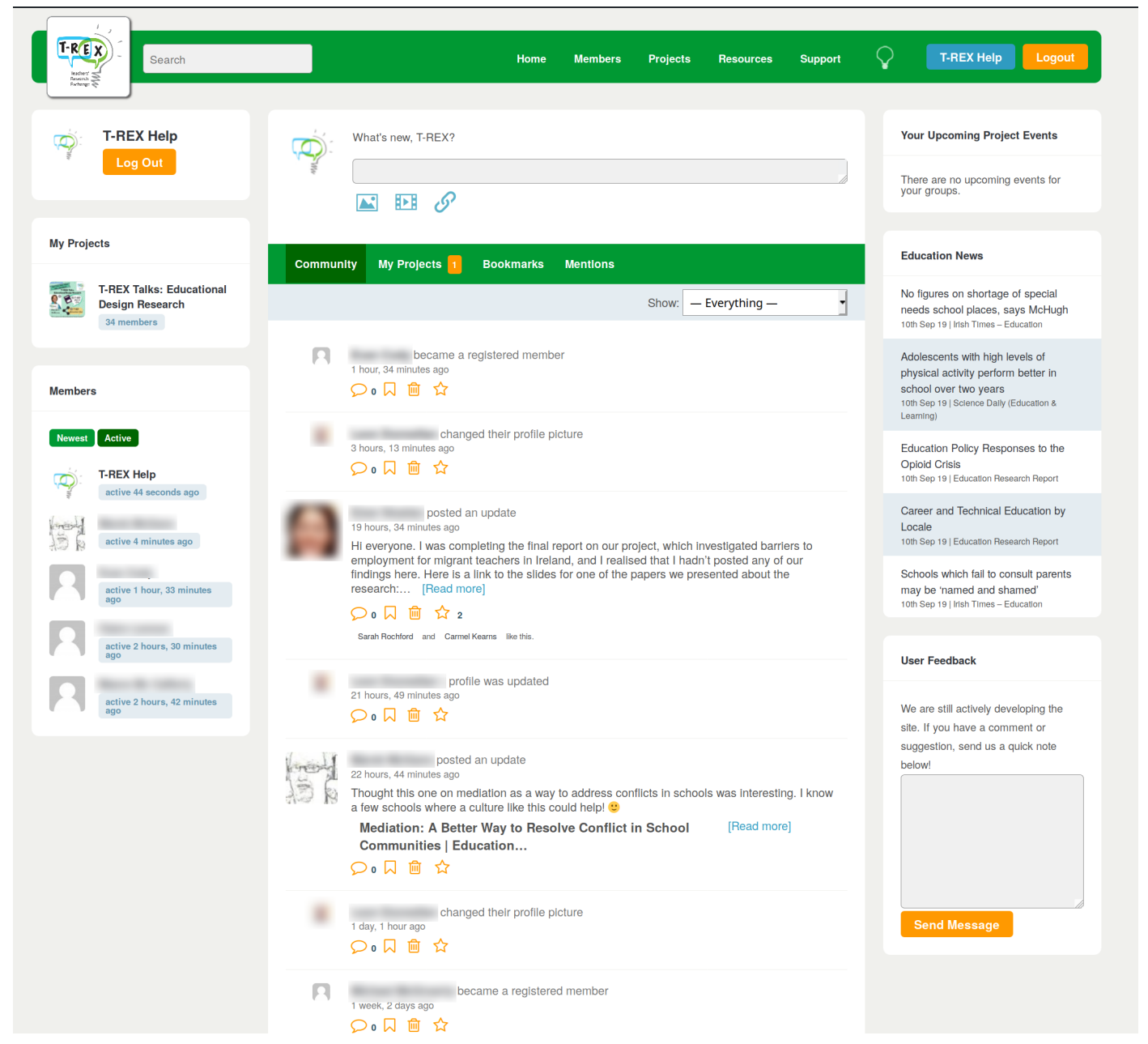

Figure 2. Screenshot of the community activity feed on T-REX.

the decision to remain local to Ireland has been largely for reasons of practical necessity).

The independence of operation also offers a continuity of engagement with the community over prolonged time in a manner not available within institutional settings. Pre-service teachers who join T-REX as part of their undergraduate studies can continue to use the same member account as they transition into the workplace as a Newly Qualified Teacher, and as their career develops further. This has led to examples of members working as students on projects with practising teachers as part of their undergraduate studies, and then returning to the play the role of the practising teacher in such collaborations in subsequent years (these "Research Team" activities are described in more detail below).

Membership of the community is primarily composed of individuals from three groups - practising teachers, pre-service teachers, and higher education professionals - though a wide variety of other professional backgrounds have at least some representation. These other backgrounds include the likes of early years education practitioners, further education professionals, and members of professional bodies and support services.

All members have access to identical user profile features. These include a chosen name and set of research interests (the only elements that are required to be publicly visible), along with details such as professional background, affiliations, biography, and qualifications. In addition, members can upload documents as personal publications, such as research reports, theses, or more formal publications, which become available and discoverable within the platform's search 
Table 1. Membership of T-REX broken down by professional setting, February 2020

\begin{tabular}{ll} 
Professional Setting & No. of Members \\
\hline Student Teacher & 1525 \\
Registered Teacher & 565 \\
Early Years Education Student & 136 \\
Early Years Education Professional & 8 \\
Further Education Professional & 17 \\
Higher Educational Professional & 216 \\
Educational Support/Services Professional & 35
\end{tabular}

features. In time, this may also help overcome the problem of masses of postgraduate or similar research never finding use in the community because it is housed only in university libraries.

All members have access to the same resources and features on the site more generally. That is, the site makes no clear distinction in terms of its functionality between pre-service teachers, practising teachers, and higher educational researchers. This ensures that practices within the community are driven by activities engaged in, rather than a fixed role assigned at registration. The resources and features can be grouped into three broad categories. The first are public components that provide the basis for a "background buzz" or sense of activity for the community. The second is a set of resources to support engagement with, and engagement in, different kinds of research activity, these are described next. The final set of resources concern collaboration and engagement with other community members, which are addressed in detail in the following section, on practice.

\subsection{The background buzz: Community activity and a curated newsfeed}

On logging in to T-REX, members are presented with the community activity feed (see screenshot, Fig.2). The community feed is a general point of congregation, or virtual public square. It is presented as a list of status updates and activities that is familiar in appearance to other social networking sites, and shared by every member of the community. Any member of the community can contribute. Updates tend to focus on announcements or the sharing of news items of wide interest within the educational community in Ireland, though users also occasionally ask advice or support from the community at large here.

Items in the community feed are principally ordered chronologically, with the most recent items appearing at the top of the list, but the presentation structure is not purely chronological. When registering for T-REX, all members are required to identify a set of research interests. Items in the community feed are then given a weighting determined by the number of research interests that overlap between them and the person posting to the feed. Posts from other members with a greater number of shared research interests essentially "age" more slowly, making it somewhat more likely that when logging in, you see posts from members who have shared interests. For instance, the posts from someone who has four shared research interests with you, will move out of your view of the community feed more slowly than someone with only one, or no shared interests. Where casual interaction with others in the community whom you have not met is made difficult by a lack of shared physical space, T-REX is designed to offer at least the possibility of serendipitous encounters with others, as well as a more general sense that at the very least the educational research community in Ireland is active, and involves people from across various professional settings.

While providing at least in-principle support for such accidental activity, the community feed is dependent on members being willing to share posts about their own work, or seek support in quite a public manner. There has been some success in modelling and successfully encouraging such 


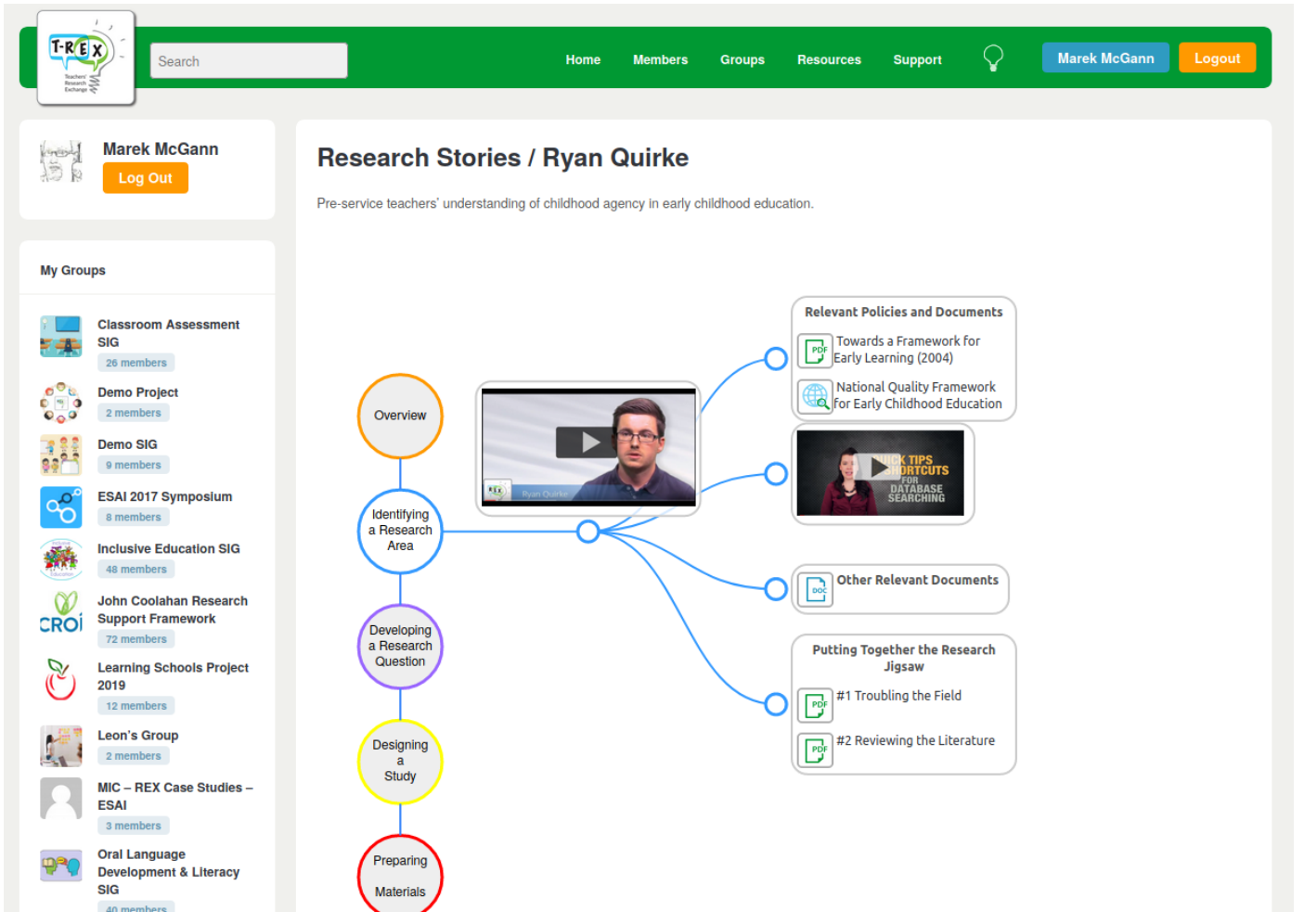

Figure 3. Screenshot of a Research Story on T-REX.

activity amongst new members, though this public square area of the site does not entirely rely upon that. In addition to user-generated activity, members have access to continuously refreshed news headlines in the form of a newsfeed (visible in the right-hand column of the screenshot in Fig. 2). This feed dynamically presents links to educationally relevant news from a number of curated sources across the web, including newspaper education supplements, educational research journals, and quality blogs on educational research.

\subsection{Research Stories: Supporting research through models and resources}

In addition to the news and public discussion on the site, T-REX provides specific resources created, and curated, to support various forms of research engagement. While the bulk of the educational value in the site exists in the way the community operates, there are explicit learning supports also available. Perhaps the most notable of these are Research Stories (see screenshot, Figure 3). Research Stories are examples of completed research projects by teacher researchers, with an emphasis in the case of these particular resources on formal research processes such as those used in academic settings. These examples are presented in a series of nine short (approximately 4 minutes) interview clips, addressing each of a structured sequence of steps in a formal research project, from deciding on a research area, reviewing the literature, to preparing materials, collection of data, and writing up. Each interview clip addresses the challenges faced that stage of the project, and how the researcher overcame those challenges. Resources, such as useful readings, document templates, or other supports, are linked to the appropriate interview segment. Members can select a project most similar to an area or research question in which they are interested, and follow the story according to their own particular needs.

These resources are intended to support those members of the community still developing their research skills, but as already noted, they play only a small part in the manner in which the T-REX community of practice works. The platform is designed at every stage to support member 
participation. The technical infrastructure supports member engagement, and it is in the members' practices, then, that we see the community in its fullest form.

\section{The Practice: Diverse activities of educational research}

Members of a community of practice are practitioners, people engaged in activities that constitute the domain in question. Though learning is central to them, it is a learning in doing, and more particularly, a learning in doing together (Wenger, 1998). T-REX provides communications and collaboration tools to all members with the aim of supporting such shared activities. Part of the development of T-REX has been the scaffolding of such shared activities, without the stipulation of a single valid or best form of practice. All engagement with the site, from reading up on recent educational news, to posting announcements or open comments, to accessing publications or learning resources, are forms of practice, though in many such cases can be done as individuals. The more directly collaborative and discursive forms of activity occur using the tools provided in groups, or as they are curently called on T-REX, Projects.

\subsection{Discussion and collaboration through T-REX Groups}

Groups are private areas of the site within which members can gather, formed for a particular purpose. Though they have several configurations, the most common is a private group, within which activity can only be seen by the group's members, though with public-facing elements that allows the group's title and brief description to be found within T-REX's directory of projects, and which also enables the possibility of sharing publications with the community - documents (e.g. research reports or other outcomes from the group's activity) posted as publicly accessible.

Projects involve a private activity feed, which any member can post to, enabling easy communication across the entire group (see Figure 4 for a screenshot). A number of other collaborative tools are also available, such as a calendar and document sharing.

Projects provide for more focused and structured activity within T-REX, and as such see the greatest amount of activity across the site. One of the principal means of assessing the success of the community to date is the number of active groups, and more crucially, the number of groups whose members include people from different professional settings. When the site was first set up, new members could indicate themselves as having one of three key backgrounds - registered teacher, student teacher, or higher educational professional (these details formed part of a person's profile on the site, but were not available to others unless the user chose to make them so). As the site has grown, and in response to feedback from other members of the educational research community, a wider range of professional settings can now be indicated, including educational professional or support services, early years educator, further education professional, and more. In the year or so that the site has been properly active, it has hosted more than three hundred projects, many of which involve collaborations across professional boundaries from two, three, or more different settings. Table 2 outlines numbers of projects with memberships including the 3 key stakeholder groups, illustrating both activity on the platform, as well as some of the extent to which the platform has enabled inter-professional dialogue and collaboration.

Projects provide for a number of different kinds of scaffolded actions. Ultimately, these are user-driven, but a number of models of use have been fostered by the development team, in collaboration with different professional groups, as part of the facilitation of the community's development.

\section{Research Teams}

Research Teams are perhaps the most compelling example of collaboration between professional groups, and illustrative of the potential of meeting the complementary needs of working teachers on 


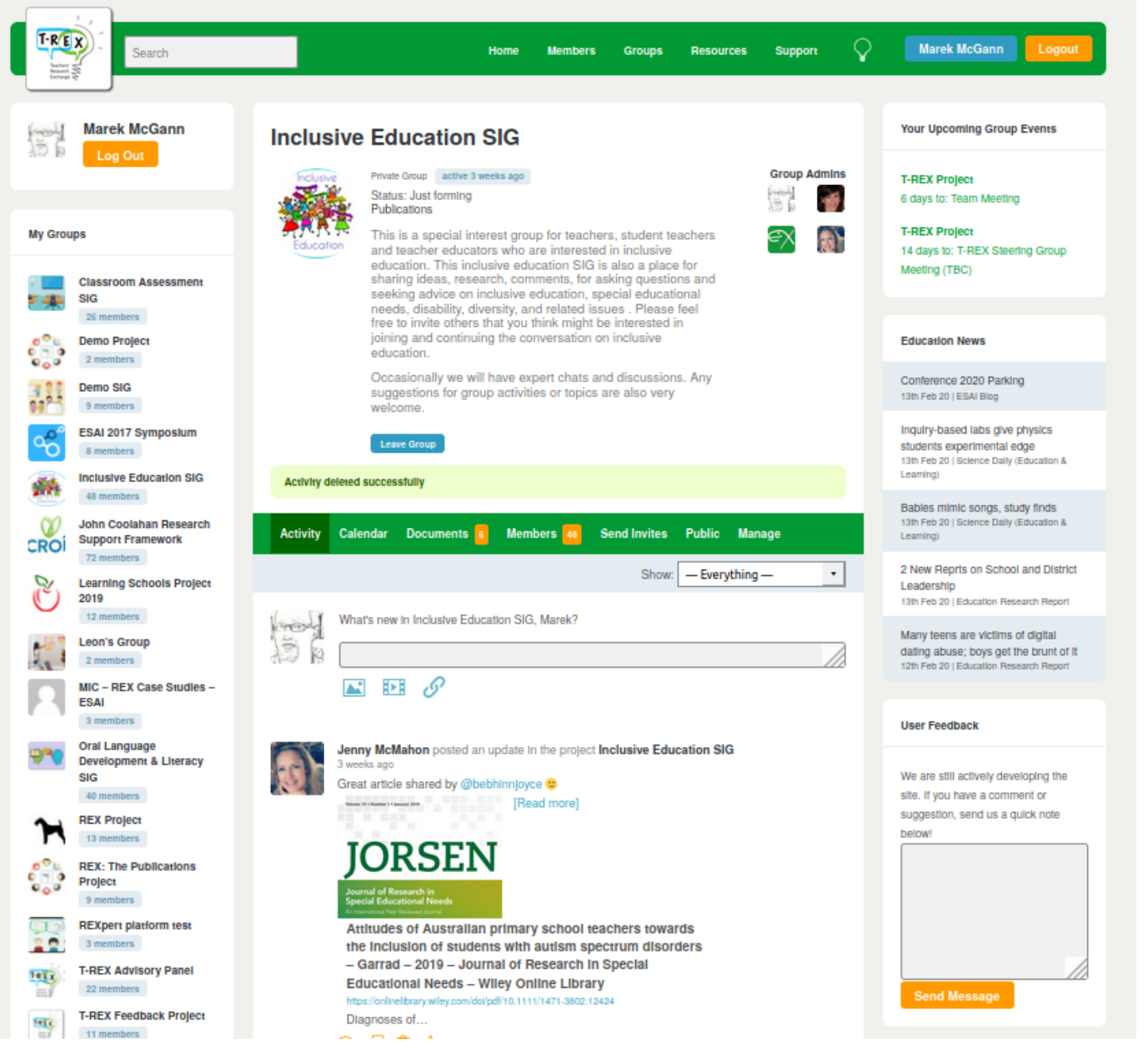

Figure 4. Screenshot of the activity feed of a T-REX Special Interest Group.

the one hand, and researchers and pre-service teachers in higher education institutions on the other. Though teachers and higher educational professionals have expressed interest in collaborations, the means by which such collaborations might form and the bridges across the research-practice gap might take shape have clearly been something of a challenge for both groups - the reason that the research-practice gap remains. The changes in policy and accreditation context within Ireland provided an opportunity to foster such collaborations, however, in the form of new requirements of research skills and research engagement for pre-service teacher during their undergraduate studies (Teaching Council of Ireland, 2011, 2017). The T-REX development team engaged higher education professionals involved in Initial Teacher Education, and in partnership with them supported the development of a "Research Teams" activity within undergraduate modules in three universities and colleges.

Teams of 4 to 6 students are formed from the enrolment in the module of an ITE programme. Practitioner partners, working teachers, are then recruited by the student team themselves (either through personal networks or by contacting T-REX members on the platform who are registered teachers), or by the academic staff on the module. These practitioners are invited to identify an area of practice or professional experience into which they would like to engage in research. This might be a topic area relevant to the module in question, or a specific research question to be examined. The inter-professional team of pre-service teachers and in-service teachers, supported by academic staff, can then develop a range of collaborative activities, from critical literature reviews, to multisite data collection and analysis. The activity can then form the basis of a problem-based learning 
Table 2. Membership of T-REX broken down by professional setting, February 2020

$\begin{array}{ll}\text { Professional Setting } & \text { No. of Projects } \\ \text { Student Teacher Only } & 159 \\ \text { Registered Teacher Only } & 9 \\ \text { Higher Education Professional Only } & 32 \\ \text { Registered Teacher, Higher Education Professional } & 17 \\ \text { Student Teacher, Registered Teacher, Higher Educational Professional } & 26\end{array}$

assessment for the students, with the teacher acting as "anchor", providing an applied perspective to help shape the students' investigations, and benefiting from the distributed research workload.

Such heavily structured activities serve two purposes. Firstly, they provide a clear means by which the required research activity of hundreds if not thousands of students can provide benefit (even if of varying quality) to in-service educators. Secondly, in grounding research-based activities in the experience of working practitioners, it legitimises the assessment activity for students, and brings into sharp focus for them how research informs educational practice. Research teams also provide a setting in which pre-service teachers get to practice professional communication (with their teacher collaborator), and are given a legitimate voice (moderated by that teacher partner) in an area of real classroom practice. Recognition of the integral role of research in the practice of the working teacher helps foster a research-engaged professional identity that often comes as something of a surprise to the students in question. Research engagement is rarely recognised as vital to the profession by students prior to their undergraduate studies, as it is a relatively "hidden" aspect of professional practice. Even during their professional preparation, it can easily be perceived as additional or separate to the core aspects of school placement and teaching practice. Research teams activities illustrates clearly how research engagement is embedded in a teacher's normal professional behaviour.

Collaborative research teams are one form of support for research engagement through projects on T-REX, one with a clear goal and constrained time-frame (associated with the learning module in question). Other project-based activities have also evolved on the platform, and been used to cultivate interaction across professional settings. One example of this is the Special Interest Group.

\section{Special Interest Groups}

Special Interest Groups (SIGs) are project groups formed for the purposes of sharing information around specific topics of value to educational professionals, such as inclusion, or language development and literacy. These are groups with intermittent activity, but enable more casual and informal discussions prompted by news items, research publications, or classroom experiences.

To enable the formation and initial recruitment of interested members for such groups, SIGs on T-REX have been seeded using online discussions with research leaders in the area. These discussions, termed T-REXpert Chats, are text-based discussions in which the research leader provides short answers to member posted questions, which provide the stimulus for further participant conversations. These conversations also offer opportunities for clarificatory dialogue between academic researchers and practising teachers, to help overcome challenges of technical vocabularies and differences of professional dialects. These structured occasions also offer a means to support users interacting in somewhat less formal settings, with possibility for back-and-forth dialogue to address issues of confusion or uncertainty, in low-stakes discussions that may allow more natural conversations between professional groups to arise (as opposed to higher-stakes formal projects where roles and power relations are more fixed).

As a text-based activity, the discussion itself remains as a reference for members as the SIG 
grows and its activity continues over the longer term. It is thus less structured a form of engagement compared with the likes of collaborative research teams, but provides an additional example of the kind of easy boundary crossing essential to the development of an inter-disciplinary community.

One final example of project-based activity, less structured again, is the support group.

\section{Support Groups}

Research is a challenging endeavour at the best of times, and even those of us who make it our profession find ourselves confronted with nebulous or ill-structured problems that are difficult to pin down. Combined with the already fleeting or evasive nature of the activity, many educational researchers, particularly graduate students or teachers engaged in part-time formal study, work in relative isolation. Some groups on T-REX have formed projects for the purposes of engaging in mutual support - a closer knit and circumscribed version of the phdchat or edchat conversations that take place on Twitter. Discussions on shared readings, or sharing of study and research experiences are enabled by the private group features, and provide a means of reaching others for informal support where the, perhaps more desirable, casual cup of coffee is impractical due to constraints of time or geography.

As T-REX has found greater reach and recognition amongst the educational community in Ireland, it has also been adopted by the national professional body, the Teaching Council, to host support groups for those teachers benefiting from their Research Support Framework, a fund dispersed with the intention of encouraging research engagement amongst working teachers in Ireland. The group involves teachers, education support professionals, and higher education professionals. As with the Chat activities mentioned above, such mixed-member support groups provide settings in which less formal discussion between professionals can take place, and be witnessed by quiet members who don't necessarily post directly themselves. Such conversations help to break down power relations and fixed perceptions of different roles within the research community of the different groups.

\section{Challenges and Future Developments}

The T-REX project has been developing since autumn of 2016. Early phases of the project were focused on stakeholder consultations and software development, such that the site saw its first fully engaged users in spring of 2017. Initially deployed in 3 higher education institutions (HEIs), it is currently being deployed on ITE modules in $5 \mathrm{HEIs}$, with teachers and other professionals from across the entire country of Ireland being involved.

Member recruitment has continued, though unsurprisingly both recruitment of new users as well as general use of the site waxes and wanes with the academic year, and particularly with the autumn and spring terms of the typical Irish university calendar. For the community of practice to stay properly "alive", a critical mass of engaged members will need to be reached, at which point T-REX will have become embedded as simply a core, assumed part of the educational research infrastructure in the country. It is impossible to know in advance what kinds of membership numbers, distribution of professions, and modes of use will constitute such a critical mass. Identifying targets for new members, beyond "more", therefore remains a challenge.

Relatedly, bringing people on to the T-REX system will involve encouraging people to move away from some existing support and discussion communities as they exist on commercial social networking platforms. T-REX provides both ethical value, in not subjecting members to minute surveillance as a cost of participating, and benefits in terms of the opportunities for inter-professional collaborations which groups on large commercial platforms tend not to (as those groups tend to be within closed professional networks). Enticing users away from already existing provisions, particularly where it is integrated with their routine social network use, is likely to be difficult. Following Wenger et al.'s (2002) principles for cultivating a community of practice, however, we have continued to 
focus on developing the particular value that T-REX can offer, in order to make the move sufficiently appealing.

The primary value of the community is in its membership, their diversity of background, and the various ways in which they can coordinate their activity for mutual benefit. In discussions with stakeholders, however, the valid question has repeatedly been raised, regarding the likely varying quality of the kinds of research conducted through the site, and published their whether via projects or users' personal profiles. The risk arises that poor quality research will spread, leading to confusion or mismanaged resources for the educational community in Ireland as a result.

Implicit in such discussions, and sometimes explicit, is the question of whether some form of editorial oversight should be applied to research outputs posted to the various channels on the site. We note that such oversight would be onerous, and largely impractical to implement. But we also note that such formal review procedures provide no panacea to the quality of research or the effective and economic management of resources. There are several examples of "education myths", that had seemed to be backed by peer-reviewed, scientific community-endorsed research and drove significant spending and effort by the teachers and schools. The question of learning styles (Pashler, McDaniel, Rohrer, Bjork, 2008) is perhaps the most famous of these, though other popular interventions have seen significant doubts cast over the strength of the effectiveness, such as that a 'growth mind-set' (Sisk, Burgoyne, Sun, Butler Macnamara, 2018). Our response to this question is two-fold. Driven by principles in open science (Munafo, et al., 2017; Nosek, Spies, Motyl, 2012), it is our intention to foster capacity for more critical engagement with research amongst the community at large, through the provision of learning resources, highlighting principles of good practices, and modelled behaviour for effective and open research. The recognition and valorisation of quality research will not achieved through tight gatekeeping by oracular reviewers, but instead by an improving culture of research quality in the whole community. In tandem with such learning supports, a number of features are planned for the site which will support post-publication peer review of member-posted research. High quality research cannot be directly imposed, but like the community itself, we believe it can be cultivated over time, and we have the benefit of the significant developments of models of practice that are currently taking place in related disciplines such as psychology.

That T-REX is underpinned by the basic principles of good research practice mean that while the present community is focused on the Irish context, nothing in the platform is unique or essentially connected to that context. Resources and other practical concerns, have meant that the present community is focused on the Irish education sector. The open scientific principles, as well as the open source technologies on which the technology has been built, mean that there are no barriers to similar platforms being rolled out in other localities. No specific use of the technology requires a user to be based in any particular country, and as resources become available, it may be the case that the existing T-REX can simply be opened to the international education research community. Some software development work to support such scaling of the system is already underway, though other practical considerations may also arise. Where teachers are more interested in collaborating with researchers within their own country, due to local regulatory or other relevant facets of professional context, being able to identify such details within user profiles and content searches on the site will need to be supported.

\section{Conclusion}

The Teachers' Research Exchange provides fertile ground for the cultivation of a vibrant community of practice for educational research. The project to date provides proof both in principle and practice that dialogues and collaborations between professions, and between different career stages of the same profession, has benefits for all.

Here, our main purpose has been to outline the background, principles, and overall structure of 
the Teachers' Research Exchange. Examination of evidence for changes in the experience of professional identities of the pre-service teachers, practising teachers, and higher education researchers involved in the community is currently being completed. However, the engagement and discourse of the various professionals, and the manner in which their practice has adapted in order to make more effective uses of the system bespeak it's potential. The project is now passing into a second significant phase of development. It is being embedded into a larger number of ITE programmes, with each putting the platform to use in new and frequently innovative ways unplanned by the development team. We are seeing the increasing coordination of practices between stakeholders in educational research, and the gradual narrowing of the research practice gap.

\section{Acknowledgements}

We are very grateful to a number of people for support and advice on the project, including Teresa O’Doherty, Gerry Mac Ruairc, Ollie McGarr, Des Carswell, David Moloney, Gwen Moore, Lorna Moylan, Anne O'Keeffe, Deirdre Ryan.

\section{Funding}

Funded by the National Forum for the Enhancement of Teaching Learning in Higher Education, and by the Research Alive! consortium (Teaching Council, National Council for Curriculum and Assessment, Centre for Effective Services)

\section{References}

Anderson, G. L., Herr, K. (2011). Scaling up "evidence-based" practices for teachers is a profitable but discredited paradigm. Educational Researcher, 40(6), 287-289.

Barab, S. A., MaKinster, J. G., Moore, J. A., \& Cunningham, D. J. (2001). Designing and building an online community: The struggle to support sociability in the inquiry learning forum. Educational Technology Research and Development, 49(4), 71-96.

Biesta, G. (2007). Why “what works” won't work: Evidence-based practice and the democratic deficit in educational research. Educational Theory, 57(1), 1-22.

Bitter, G., Puglisi, J., Gorges, A., \& Uppal, H. K. (2016). The effects of an online collaborative elementary math program using team-based games to improve student math achievement, attitude and motivation. International Journal for Innovation Education and Research, 4(6), 113-138.

British Educational Research Association \& Royal Society of arts (Great Britain), (2014a). Research and the teaching profession: Building the capacity for a self-improving education system: final report of the BERA-RSA inquiry into the role of research in teacher education.

British Educational Research Association \& Royal Society of Arts (Great Britain).(2014b). The role of research in teacher education: Reviewing the evidence (Interim report of the BERA-RSA Inquiry).

Broekkamp, H., \& van Hout-Wolters, B. (2007). The gap between educational research and practice: A literature review, symposium, and questionnaire. Educational Research and Evaluation, 13(3), 203-220. https://doi.org/10.1080/13803610701626127

Cain, T. (2015). Teachers' engagement with published research: Addressing the knowledge problem. The Curriculum Journal, 26(3), 488-509. https://doi.org/10.1080/09585176.2015.1020820

Coburn, C. E., Penuel, W. R., \& Geil, K. E. (2013). Research-practice partnerships: A strategy for leveraging research for educational improvement in school districts. Retrieved from William $\mathrm{T}$. Grant Foundation website: https://eric.ed.gov/?id=ED568396

Cochran-Smith, M., \& Lytle, S. L. (1999). The teacher research movement: A decade later. Educational Researcher, 28(7), 15-25.

Davies, B. (2003). Death to critique and dissent? The policies and practices of new managerialism and of'evidence-based practice'. Gender and Education, 15(1), 91-103. 
Farley-Ripple, E., May, H., Karpyn, A., Tilley, K., \& McDonough, K. (2018). Rethinking connections between research and practice in education: A conceptual framework. Educational Researcher, 47(4), 235-245.

Godfrey, D. (2016). Leadership of schools as research-led organisations in the English educational environment: Cultivating a research-engaged school culture. Educational Management Administration \& Leadership, 44(2), 301-321.

Gore, J. M., \& Gitlin, A. D. (2004). [re] visioning the academic-teacher divide: Power and knowledge in the educational community. Teachers and Teaching, 10(1), 35-58.

Hammersley, M. (1997). Educational research and teaching: A response to David Hargreaves' TTA lecture. British Educational Research Journal, 23(2), 141-161.

Hammersley, M. (2003). Can and should educational research be educative? Oxford Review of Education, 29(1), 3-25

Hammersley, M. (2005). Is the evidence-based practice movement doing more good than harm? Reflections on lain Chalmers' case for research-based policy making and practice. Evidence \& Policy: A Journal of Research, Debate and Practice, 1(1), 85-100.

Hargreaves, D. (1996). Teaching as a research-based profession: Possibilities and prospects (The Teacher Training Agency Lecture 1996). Teacher Training Agency, London.

Heft, H. (2001). Ecological psychology in context: James Gibson, Roger Barker, and the legacy of William James's radical empiricism. (1st ed.). Lawrence Erlbaum Associates.

Inspectorate, Department of Education and Skills. (2016). School self-evaluation guidelines: 2016-2020. Retrieved from https://www.education.ie/en/Publications/Inspection-Reports-Publications/EvaluationReports-Guidelines/School-Self-Evaluation-Guidelines-2016-2020-Primary.pdf

Jacoby, J. J., Gorges, B. B., Gibbs, P., \& others. (2018). BuddyPress.org. Retrieved April 5, 2018, from BuddyPress website: https://buddypress.org/

Joram, E. (2007). Clashing epistemologies: Aspiring teachers', practicing teachers', and professors' beliefs about knowledge and research in education. Teaching and Teacher Education, 23(2), 123-135.

Lave, J., \& Wenger, E. (1991). Situated learning: Legitimate peripheral participation. Cambridge: Cambridge University Press.

Lee, K., Brownstein, J. S., Mills, R. G., \& Kohane, I. S. (2010). Does collocation inform the impact of collaboration? PLoS One, 5(12), e14279. https://doi.org/10.1371/journal.pone.0014279.

Levin, B. (2004). Making research matter more. Education Policy Analysis Archives, 12, 56.

MacPhail, A., \& O'Sullivan, M. (2019). Challenges for Irish teacher educators in being active users and producers of research. European Journal of Teacher Education, 42(4), 492-506.

McAvinia, C., \& Maguire, T. (2011). Evaluating the National Digital Learning Repository (NDLR): New models of communities of practice. All Ireland Journal of Higher Education, 3(1), 1-18.

McIntyre, D. (2005). Bridging the gap between research and practice. Cambridge Journal of Education, 35(3), 357-382.

Mims, C., Polly, D., Shepherd, C., \& Inan, F. (2006). Examining PT3 projects designed to improve preservice education. TechTrends, 50(3), 16-24.

Mockler, N. (2011). Beyond 'what works': Understanding teacher identity as a practical and political tool. Teachers and Teaching, 17(5), 517-528.

Munafò, M. R., Nosek, B. A., Bishop, D. V., Button, K. S., Chambers, C. D., Du Sert, N. P., et al. (2017). A manifesto for reproducible science. Nature Human Behaviour, 1(1), 0021.

Nisbet, J. (2005). What is educational research? Changing perspectives through the 20th century. Research Papers in Education, 20(1), 25-44.

Nosek, B. A., Spies, J. R., \& Motyl, M. (2012). Scientific utopia: II. Restructuring incentives and practices to promote truth over publishability. Perspectives on Psychological Science, 7(6), 615-631. 
OECD. (2007). Evidence in education: Linking research and policy. Retrieved from OECD website: http://www.oecd.org/education/ceri/evidenceineducationlinkingresearchandpolicy.htm

Pashler, H., McDaniel, M., Rohrer, D., \& Bjork, R. (2008). Learning styles: Concepts and evidence. Psychological Science in the Public Interest, 9(3), 105-119.

Penuel, W. R. (2015). Infrastructuring as a practice for promoting transformation and equity in designbased implementation research. Keynote presentation at the meeting of the International Society for Design and Development in education conference, Boulder, Colorado, Http://Learndbir. Org/talks-and-papers/Infrastructuring-as-a-practice-for-promoting-transformation-and-equityin-design- based-implementation-Research-2015.

Penuel, W. R. (2019). Infrastructuring as a practice of design-based research for supporting and studying equitable implementation and sustainability of innovations. Journal of the Learning Sciences, 1-19.

Renninger, K. A., \& Shumar, W. (2002). Community building with and for teachers at the math forum. In K. A. Renninger \& W. Shumar (Eds.), Building virtual communities: Learning and change in cyberspace (Vol. 129, p. 158). Cambridge University Press.

Sahlberg, P., \& Hasak, J. (2016). Next big thing in education: Small data-Pasi Sahlberg. Washington Post. Retrieved from https://pasisahlberg.com/next-big-thing-education-small-data/

Schlager, M., Fusco, J., \& Schank, P. (2002a). Evolution of an online education community of practice. In K. A. Renninger W. Shumar, Building virtual communities: Learning and change in cyberspace (Vol. 129, p. 158). Cambridge University Press.

Schlager, M., Fusco, J., \& Schank, P. (2002b). Cornerstones for an on-line community of education professionals. IEEE Technology and Society Magazine, 17(4), 15-21.

Schlager, M. S., \& Fusco, J. (2003). Teacher professional development, technology, and communities of practice: Are we putting the cart before the horse? The Information Society, 19(3), 203-220. https://doi.org/10.1080/01972240309464.

Schoggen, P. (1989). Behavior settings: A revision and extension of Roger G. Barker's "Ecological Psychology." Stanford University Press.

Schwartz, M. S., \& Gerlach, J. (2011). Guiding principles for a research schools network: Successes and challenges. Mind, Brain, and Education, 5(4), 172-179. https://doi.org/10.1111/j.1751228X.2011.01125.X

See, B. H., Gorard, S., \& Siddiqui, N. (2016). Teachers' use of research evidence in practice: A pilot study of feedback to enhance learning. Educational Research, 58(1), 56-72.

Sisk, V. F., Burgoyne, A. P., Sun, J., Butler, J. L., \& Macnamara, B. N. (2018). To what extent and under which circumstances are growth mind-sets important to academic achievement? Two meta-analyses. Psychological Science, 29(4), 549-571.

Slavin, R. E. (2008). Perspectives on evidence-based research in education-What Works? Issues in synthesizing educational program evaluations. Educational Researcher, 37(1), 5-14. https://doi.org/10.3102/0013189X08314117

Stenhouse, L. (1981). What counts as research? British Journal of Educational Studies, 29(2), 103-114.

The Teaching Council. (2011). Initial teacher education: Strategy for the review and professional accreditation of existing Programmes. Maynooth: The Teaching Council.

The Teaching Council. (2017). Initial teacher education: Criteria and guidelines for Programme providers. Maynooth: The Teaching Council.

Ulichny, P., \& Schoener, W. (1996). Teacher-researcher collaboration from two perspectives. Harvard Educational Review, 66(3), 496-525.

U.S. Department of Education. (2014). Designing online communities of practice for educators to create value. U.S. Department of Education. https://tech.ed.gov/designing-online-communitiesof-practice/ 
Vanderlinde, R., van Braak, J. (2010). The gap between educational research and practice: Views of teachers, school leaders, intermediaries and researchers. British Educational Research Journal, 36(2), 299-316.

Walker, M., Nelson, J., Bradshaw, S., Brown, C. (2018). Teachers' engagement with research: What do we know? A research briefing. Millbank: Education Endowment Foundation.

Wenger, E. (1998). Communities of practice: Learning, meaning, and identity. Cambridge: Cambridge University Press.

Wenger, E., McDermott, R. A., Snyder, W. (2002). Cultivating communities of practice: A guide to managing knowledge. Cambridge: Harvard Business Press. 